\title{
Mitigation Options for Future Water Scarcity: A Case Study in Santa Cruz Island (Galapagos Archipelago)
}

\author{
Maria Fernanda Reyes ${ }^{1, *}$, Nemanja Trifunović ${ }^{1}$, Saroj Sharma ${ }^{1}$, Kourosh Behzadian ${ }^{2}$ (iD, \\ Zoran Kapelan ${ }^{3}$ and Maria D. Kennedy ${ }^{1,4}$ \\ 1 Department of Environmental Engineering and Water Technology, UNESCO-IHE Institute for Water \\ Education, P.O. Box 3015, 2601 DA Delft, The Netherlands; n.trifunovic@un-ihe.org (N.T.) \\ s.sharma@un-ihe.org (S.S.); m.kennedy@un-ihe.org (M.D.K.) \\ 2 Centre for Water Systems, School of Engineering, University of West London, London W5 5RF, UK; \\ kourosh.behzadian@uwl.ac.uk \\ 3 College of Engineering, Mathematics and Physical Sciences, University of Exeter, Exeter EX4 4QF, UK; \\ z.kapelan@exeter.ac.uk \\ 4 Faculty of Civil Engineering and Geosciences, Delft University of Technology, P.O. Box 5048, 2600 GA Delft, \\ The Netherlands \\ * Correspondence: fersireyes@hotmail.com; Tel.: +31-(0)1-5215-1715
}

Received: 1 May 2017; Accepted: 9 August 2017; Published: 12 August 2017

\begin{abstract}
Santa Cruz Island (Galápagos Archipelago), like many other tourist islands, is currently experiencing an exponential increase in tourism and local population growth, jeopardizing current and future water supply. An accurate assessment of the future water supply/demand balance is crucial to capital investment for water infrastructure. This paper aims to present five intervention strategies, which are suggested to solve the future water crisis. The strategies combined include environmentally sustainable options such as rainwater harvesting, greywater recycling and water demand management, as well as desalination. These strategies were evaluated under four population growth scenarios (very fast, fast, moderate and slow growths) by using several Key Performance Indicators (KPI's) including water demand, leakage levels, total costs, energy consumption, rainwater delivered and greywater recycled. Moreover, it also aims to develop a methodology for similar islands, using the WaterMet ${ }^{2}$ modelling approach, a tool for integrated of sustainable-based performance of urban water systems. The results obtained show that by 2044 only a small portion of the future water demand can be covered assuming business as usual. Therefore, desalination seems to be the most viable option in order to mitigate the lack of water at the end of the planning period considering the growth trends. However, strategies comprising more environmentally friendly alternatives may be sufficient, but only under slow population growth scenarios.
\end{abstract}

Keywords: intervention strategy; key performance indicators; water demand prediction; water scarcity; WaterMet ${ }^{2}$

\section{Introduction}

Santa Cruz is the main tourist island in the Galápagos Archipelago, located around the Equator on the Pacific Ocean, holding more than $60 \%$ of total local population and visitors [1]. The island has two main towns of Puerto Ayora and Bellavista with 12,000 and 2500 inhabitants respectively [2]. Furthermore, the number of tourist arrivals in 2013 was approximately 204,000 [3]. As a consequence of the exponential and unsustainable growth rates of tourism and local population, the demand for public services has increased exponentially, especially in Puerto Ayora, the main centre of tourist activities. Due to the fast economic development of the island, priority is given to tourism without considering the related environmental impacts [4]. The demand for natural resources such as potable 
water has abruptly increased, resulting in deficient water supply services and contributing to fast ecological degradation.

Due to the uncontrolled expansion of tourism [5], touristic premises have increased with annual growth rates between $8 \%$ and $11 \%$ [6]. The fragile ecosystem is further endangered by the increasing number of immigrants coming from the mainland, contributing to annual population growth rates of almost $5 \%$ in 2010, (from $2.5 \%$ in 1960). Consequently, local authorities have been facing serious challenges to cope with this and the adequate provision of basic services due to limited financial resources, limited water resources and lack of required infrastructure. The main reasons for these limitations can be found in some factors such as weak and unstable governance, lack of policies considering the ecosystem, unplanned urbanisation and fast economic development [2,7]. Moreover, land-based tourism has predominated, requiring greater urban development and supporting infrastructure, more severe depletion of drinking water resources, consumption of energy, etc. [8].

Currently, the water supply on the island is intermittent, with an average supply of three hours per day. Also, several studies have assessed water losses as high as $70 \%$ [9] or more recently, 35\% of system input volume as Non-Revenue Water (NRW) [7]; this is caused by ageing networks and the lack of proper maintenance. In addition, there is excessive water loss within premises in the form of leaks and overflows from tanks, which is likely to be the consequence of fixed water tariff structures in Puerto Ayora [10].

Estimation of water demand in the Santa Cruz Island is difficult due to the lack of water meters for customers in Puerto Ayora. Next to the municipal supply, there are numerous extractions from crevices by individuals and/or institutions (contributing to the unknown demand due to the lack of records), and bottled-desalinated water is distributed by small private companies. However, there have been some studies about water demand estimations for the island. The water demand based on data from Puerto Ayora, considering 13 installed water meters, suggested that the specific water demand ranged from 92 to $1567 \mathrm{~L} / \mathrm{cap} /$ day, suggesting that some domestic premises are also (informal) tourist accommodations [11]. A recent study by [12] estimated the water demand per category of users, considering all sources of water as shown in Table 1. Based on this analysis, the specific water demand in Puerto Ayora was estimated to be between 163 and $177 \mathrm{~L} / \mathrm{cap} /$ day where the former figure corresponds to municipal demand and the latter one to total domestic water demand.

Table 1. Total water demand quantification for Puerto Ayora for different categories [12].

\begin{tabular}{ccccc}
\hline Category & $\begin{array}{c}\text { Municipal } \\
\text { Supply }\left(\mathbf{m}^{\mathbf{3}} / \mathbf{d a y}\right)\end{array}$ & $\begin{array}{c}\text { Bottled Water } \\
\left(\mathbf{m}^{\mathbf{3}} / \mathbf{d a y}\right)\end{array}$ & $\begin{array}{c}\text { Water Trucks } \\
\left(\mathbf{m}^{\mathbf{3}} / \mathbf{d a y}\right)\end{array}$ & $\begin{array}{c}\text { Total Demand } \\
\left(\mathbf{m}^{\mathbf{3}} / \mathbf{d a y}\right)\end{array}$ \\
\hline Domestic & 1951 & 20 & 158 & 2129 \\
Hotels & 1107 & 21 & 1789 & 2917 \\
Restaurants & 69 & 8 & 51 & 128 \\
Laundries & 29 & 0 & 20 & 49 \\
TOTAL & 3156 & 48 & 2018 & 5222 \\
\hline
\end{tabular}

Although the above-mentioned studies have intensively estimated existing water demand, none of them have tried to forecast future water demand in relation to water availability, developing a water balance for the next 30 years. This may seriously endanger the future of the island's development with respect to the highly increasing water demands, affecting not only local population and tourism, but the fragile ecosystem as well.

Based on the above, the current study aims to develop a water balance model for Puerto Ayora, in order to compare the baseline conditions (business as usual) with a number of possible intervention strategies to meet future demand, under different scenarios of population growth rates. This should enable decision makers to investigate the impact of population growth on the level of water services on Santa Cruz Island. The model considers a 30-year period during which four different population/tourist growth scenarios are analysed using the WaterMet ${ }^{2}$ model (University of Exeter, UK)) [13]. 
First, a brief literature review of water demand forecasting using Urban Water Systems (UWS) models and further details of the WaterMet ${ }^{2}$ model are presented in the next section. Later, the methodology and assumptions applied to the analysed case study are introduced, followed by the description of the modelling approach. This methodology is then applied to the case study of Santa Cruz. Subsequently, the results are presented and discussed and, at the end, several conclusions are drawn.

\section{Literature Review}

\subsection{Urban Water System Modelling Approach}

Owing to the increase in computational power and computer technologies, the modelling of UWS has shifted towards more holistic approaches rather than viewing each process separately. Processes are considered as components of a whole, complete and integrated water cycle [14]. According to [15], the primary objective of the UWS analyses should be first to balance out demand with supply. Therefore, the water demand forecast has been developed mainly to understand spatial and temporal patterns of water use in the future [16], as well as for better management of water resources [17]. Water demand forecasting has encountered many problems due to the nature and quality of available data, numerous variables that are hypothesized to affect demand, and the variety of forecast horizons [18].

There are several types of urban water cycle models: (1) detailed models (Infoworks, SMURF, Hydro Planner), which are characterized by their limited scope and high data requirements; (2) catchment scale models (Water StrategyMan, Aquatool (Mitchell et al., 2010) [19], Systems Modelling RioGrande), characterized by wide system boundaries, but do not provide sufficient analysis of the urban water system at sub-city scale; (3) urban water scoping programs (UWOT-University of Exeter [20], UK, Aquacycle [19], UVQ-CSIRO, Australia, WaterCress, CWB-University of Birmingham, UK [21], WaterMet ${ }^{2}$ [13], which model city scale dynamics including all of the important processes within the urban water cycle (but in less detail than more focused models).

The latter ones are suitable to be used as sustainability assessment tools and for strategic planning. They forecast water demand and include the main components of the urban water cycle in a holistic and integrated approach. These models strive to include water supply, stormwater, wastewater and groundwater by considering both aspects of water quantity and quality simulation.

WaterMet ${ }^{2}$ is a metabolism-based model which quantifies a number of flows/fluxes (e.g., water and energy) in urban water systems (UWS) [22], and can be used for the assessment of sustainability-based performance of the analyzed water system, including quantifying the likely impact of different intervention strategies. Therefore, WaterMet ${ }^{2}$ was found to be the most suitable in this study with respect to the data availability. Also, the aspects of modelling the water cycle in the UWS, as different and separate components made it appropriate for this case study, since there is no sewage system and only the supply and demand component could be modelled. Moreover, it concurrently forecasted water demand under various scenarios and evaluated the performance of several strategic solutions for a water supply problem [23]. Also, this model is able to represent the daily, seasonal, and annual (future) dynamics of the water demand (i.e., caused by demography or changes in consumption pattern). Furthermore, it has a wide range of output indicators resulting from the simulation of wide range of fluxes: water flow, energy flow, greenhouse gas emission, among other, which offers several sustainability indicators for assessment of the intervention strategies.

Unlike the previously mentioned models, data input requirements were extent and focused on the modelling of other aspects but future water demand coverage. Furthermore, due to its conceptual nature, modelling the UWS in WaterMet ${ }^{2}$ can be achieved with relatively little input data. This has been an important attribute and specifically a significant constraint for many cases, especially in developing countries. The lack of substantial and historic data has limited the development of different strategies that allow improvement in water demand and supply management. Also, none of the other models is considered as a holistic systemic perspective for the analysis of resource flows and 
their impacts on the future performance of UWS. Furthermore, this model allows to examine selected intervention strategies for a long-term planning. These two characteristics are addressed through a metabolism-based approach, which refer to the different fluxes and conversion processes related to all water flows, materials and energy in a UWS. With this approach, decision makers are able to identify critical components that have more or less impact in sustainability, and it allows the minimization of negative environmental impact by applying intervention strategies that save water, as well as energy, chemicals and costs. Thus, it presents a generic modeling approach based on WaterMet ${ }^{2}$ that can be used to address the long-term supply demand balance under data scarcity conditions.

WaterMet ${ }^{2}$ is a quantitative UWS performance model, which simulates mass balances throughout the whole urban system and calculates the principal water-related flows [13]. It also models future urban water balance and cycle, and specifies key performance indicators which can be used for evaluation of alternative intervention strategies under a number of different scenarios. The urban water cycle is simulated within four main subsystems referred to as water supply, water demand, wastewater, and water recovery (Figure 1).

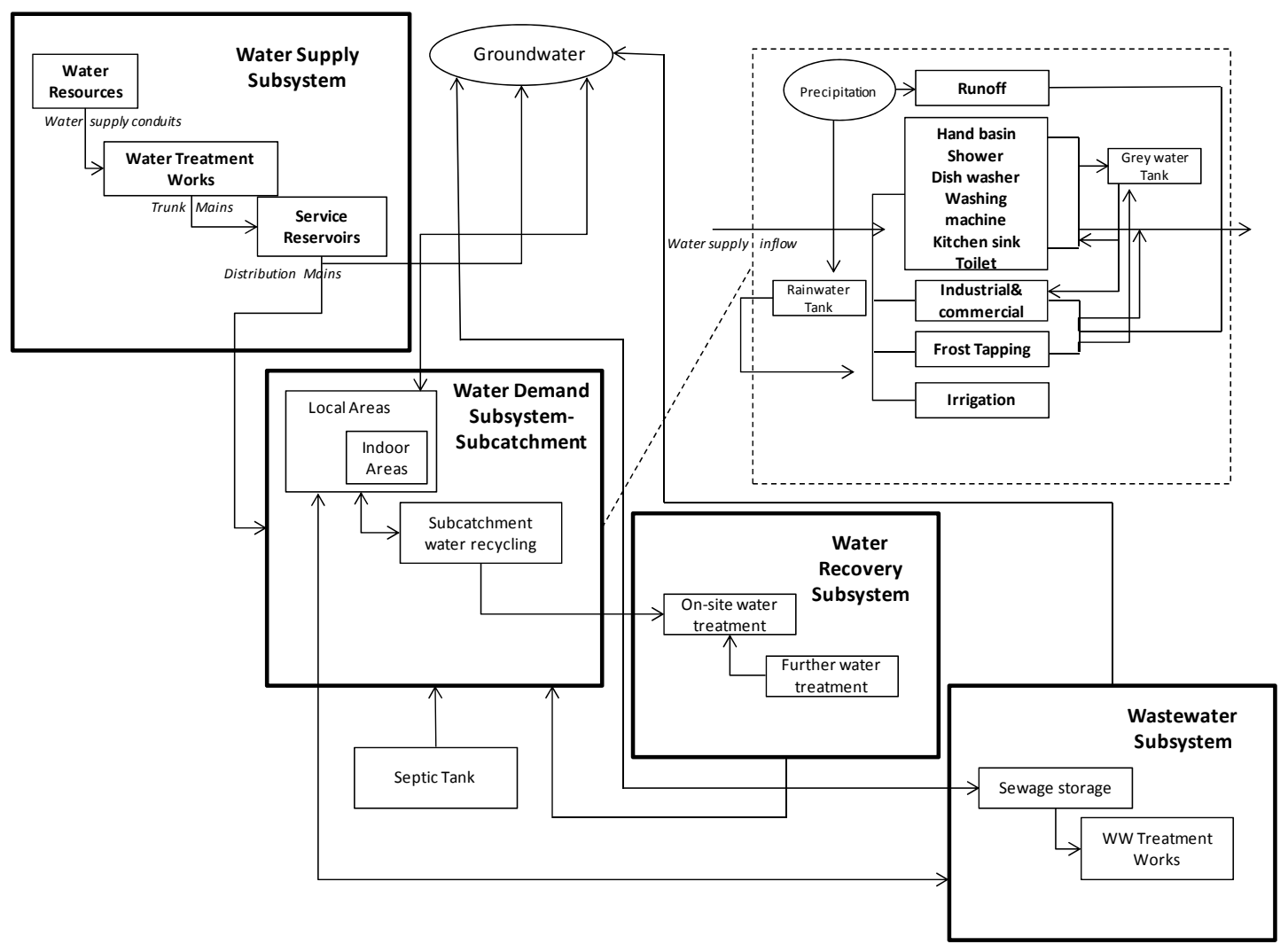

Figure 1. Components used for modelling different spatial levels in WaterMet ${ }^{2}$.

Modelling of UWS using WaterMet ${ }^{2}$ adopts specific spatial and temporal limits. There are four spatial scales represented by the model: (1) indoor area (e.g., residential, industrial, commercial, and public properties); (2) local area as a group of similar properties and same characteristics; (3) subcatchment area as a group of neighbouring local areas and (4) city area. There are different temporal scales for the simulation of UWS performance over a long-term planning horizon such as annual, monthly and daily variations.

\subsection{Population and Tourism Growth Scenarios}

Population projection is very important in these types of studies because it shows the interaction of an UWS in the future. Generally, these types of projections gather three factors such as mortality, 
fertility and/or migration. In order to project the size of a population in the future, many assumptions have to be made regarding the different factors that may influence the tendency of growth and how they will change over the selected period of time. In the case of the WaterMet ${ }^{2}$ software, the growth needs to be specified for each year included in the planning horizon.

\subsection{Alternatives and Intervention Strategies}

The WaterMet ${ }^{2}$ model allows the proposition of several types of intervention strategies, which might help improve the UWS performance when dealing with increasing water demands in the future. Among them are leakage reduction levels, pipe rehabilitation, water demand management, water meter installation, rainwater harvesting (RWH) and greywater recycling (GWR). The impact of these alternatives can be evaluated through different KPIs on the software. The KPIs can be further used as measurements for the evaluation of specific criteria, especially when comparing different scenarios or introducing different options in the model.

\section{Methodology}

In this study, the WaterMet ${ }^{2}$ model was used to forecast the urban water balance for a future 30-year period. First, four different growth scenarios were chosen to predict and assess future water demand based on previous studies. Afterwards, after sufficient literature review, the model was built for a Puerto Ayora case study and the baseline condition (business as usual) was analysed in order to develop relevant strategies that will solve the future water deficit. Based on this, six water supply and demand management alternatives (individual strategies) were analysed in the Puerto Ayora model. The impact of each of these alternatives to meet future water demand was assessed by analysing the percentage of coverage of water demand with supply at the end of the planning horizon (KPI used was fraction of water demand delivered).

Due to the low fractions of water demand delivered at the end of the planning horizon, these individual alternatives were further combined in order to improve the future coverage of water demand with supply, developing five more complex intervention strategies. These new strategies combined also several sustainable options, recurring to desalination as the last option. These analysed strategies were compared using a number of KPIs in order to analyse the impact of the selected growth rates on different aspects of water demand and water supply over the period selected. The KPIs used include the ratio of water delivered to consumers, total costs (i.e., capital and Operations \& Management) and total energy use (i.e., direct and embodied). With these indicators, each strategy was assessed in order to find the most sustainable and most optimal solution for this case study, considering the fragility of the ecosystem, which will be addressed in the discussion.

Finally, conclusions were drawn, assessing all the KPI's used and the extension to which each strategy would comply at the end of the planning horizon. The intention was to portray to local authorities and stakeholders the limitations and benefits of each strategy included in this study.

\section{Case Study}

\subsection{Description}

The case study analysed here is the water supply system in the main urban settlement (Puerto Ayora) on Santa Cruz Island, considered in the model as the 'baseline condition'. The schematic representation of the water supply system of Puerto Ayora is shown in Figure 2. Here, the water is abstracted from crevice 'La Camiseta' by two pumps of $25 \mathrm{hp}$, leading to average supply of $3024 \mathrm{~m}^{3} /$ day. There is no water treatment; therefore the groundwater withdrawn, which is slightly brackish, is directly distributed to the households. The water is further conveyed over a distance of $2800 \mathrm{~m}$ to two reservoirs with the volume of $600 \mathrm{~m}^{3}$ and $800 \mathrm{~m}^{3}$, respectively, through two PVC pipes of $315 \mathrm{~mm}$. The water is then distributed to consumers by gravity, one supplying the northern part of the town and the other the southern part. The distribution network has 2156 connections (registered 
up until December 2013). There are no individual water meters installed for consumers and a fixed monthly tariff is applied based on the category of customers (domestic, commercial, touristic, etc.). The distribution network is approximately 30 years old and consists of PVC pipes of diameter ranging from 63 to $250 \mathrm{~mm}$. The total NRW is estimated to be $\pm 35 \%$, based on some surveys on the consumption of domestic households, hotels, restaurants and laundries [10]. NRW is equal to water losses plus unbilled authorised consumption [24]. However, due to negligible unbilled authorised consumption in the case study, it is assumed that water losses are equal to non-unbilled authorised consumption. As a result, an estimated value of $35 \% \mathrm{NRW}$ is assumed to be total water losses in the case study. However, for model building purposes, we have chosen $28 \%$ of leakage level, instead of $35 \%$ as initially intended, mainly due to calibration purposes of the model.

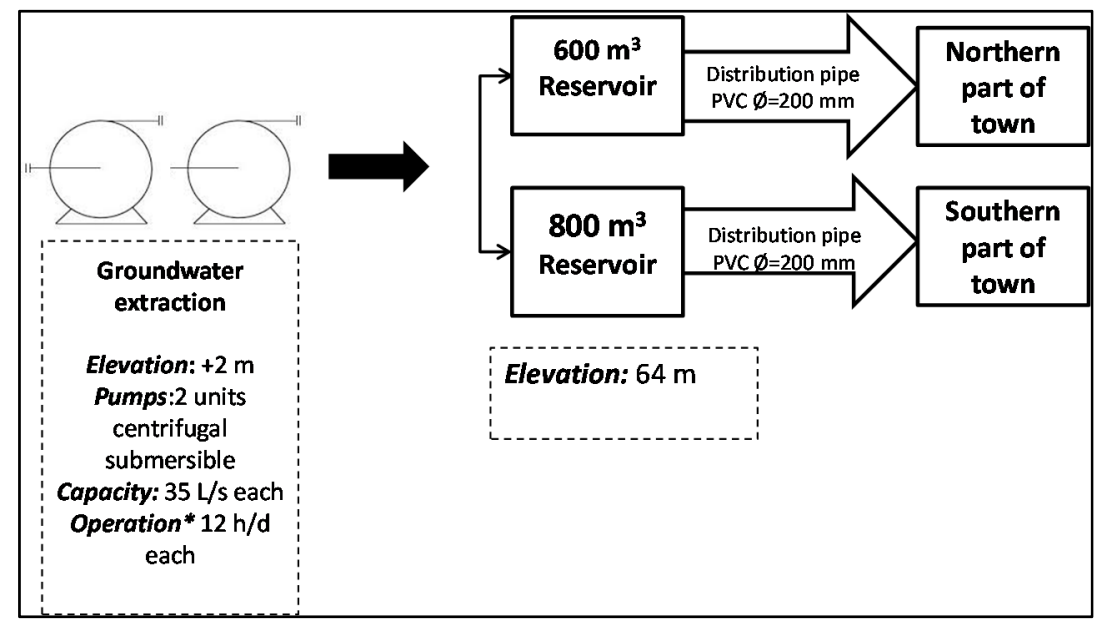

Figure 2. Current layout of Puerto Ayora water supply system; * Operation is only $12 \mathrm{~h}$ per day due to lack of sufficient power capacity for the three existing pumps to operate full time. As a result, only two operate at the same time for the specified period.

\subsection{WaterMet ${ }^{2}$ Model Building}

The main input data to model the UWS in WaterMet ${ }^{2}$ are shown in Figure 3 and are divided into three primary categories: 'Water Supply', 'Subcatchment' and 'Water Resource Recovery'. This figure differs from Figure 1 because it describes how the model is built based on the input data requirements for each component/subsystem.

The 'Water Supply' specifications of the water supply conduits, trunk mains and distribution mains include storage capacity, initial volume as well as energy, chemicals and cost used per unit volume of water. Also, the transmission component of the water supply system, which is the connecting flow routes for conveying water between storage components in the WaterMet ${ }^{2}$ model, is specified here as well. Their general specifications include transmission capacity, leakage, energyand Operations \&Management costs per unit volume of transmitted water. The detailed input data of water supply components used in the WaterMet ${ }^{2}$ model for Puerto Ayora is presented in Table 2 . The energy equation shown below is used to calculate the energy requirements of pumps as one of the requirements of the WaterMet ${ }^{2}$ in energy consumption of components in the water supply subsystem. Therefore, the theoretical energy consumption was calculated based on the equation [25]:

$$
N=\frac{\rho g Q h_{p}}{\eta_{p}}
$$

where $\rho$ is density $\left(\mathrm{kg} / \mathrm{m}^{3}\right), g$ is gravity constant $\left(\mathrm{m} / \mathrm{s}^{2}\right), Q$ refers to the flow $\left(\mathrm{m}^{3} / \mathrm{s}\right), h_{p}$ refers to the pumping head $(\mathrm{m})$ and $\eta_{p}$ is the efficiency of the pump. 


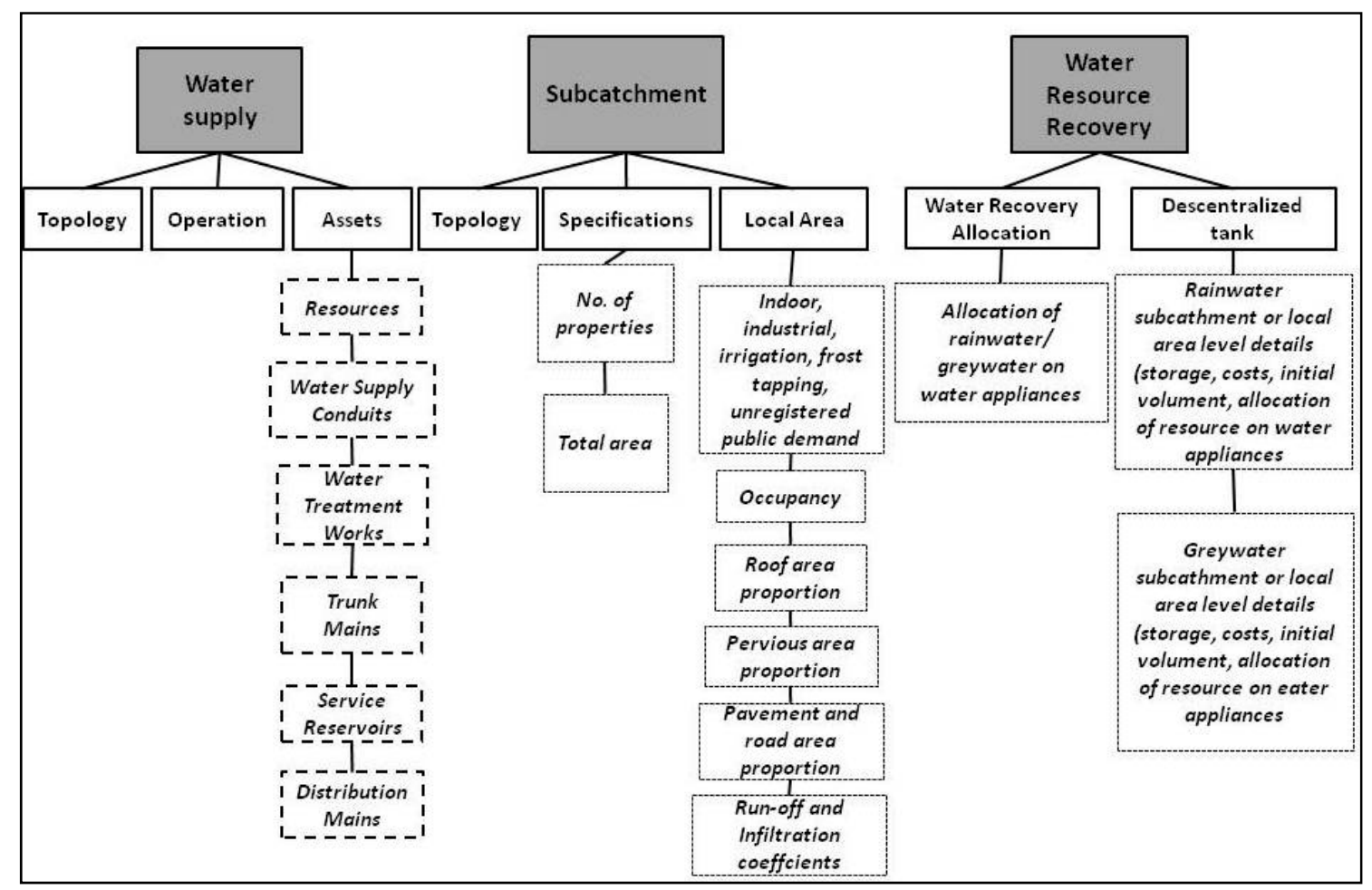

Figure 3. Main Urban Water Systems (UWS) components used in the WaterMet ${ }^{2}$ model.

The sub-catchment and local area components were used in WaterMet ${ }^{2}$ to define water demand categories and rainfall-run off characteristics of the model. Each settlement was represented as a single sub-catchment with a single local area. In Puerto Ayora, two water demand categories were defined: (1) 'indoor' water representing domestic water use; and (2) 'industrial' representing water demands of restaurants, hotels and laundries. The percentage share of water use for appliances and fittings in domestic water consumption in both cases were assumed to be $7 \%$ for hand basin, $20 \%$ for kitchen sink, $24 \%$ for showers and $49 \%$ for toilet flushing, based on a study made by [26]. Furthermore, rainfall-run off simulation was modeled considering run off from roofs only (local area level). For the software calculations, roof area proportion and pervious areas proportions were determined. A summary of the input data used for modelling the sub-catchment components in WaterMet ${ }^{2}$ is given in Table 3. The water demand variations of local areas can be defined in WaterMet ${ }^{2}$ for different temporal scales (i.e., annually and monthly). The annual variations were analysed under four selected population growth scenarios while the monthly variations were adjusted during the model calibration process, which will be discussed later. Despite the fact that in many touristic islands, there is a significant seasonal variation regarding summer and winter, there is no significant change in the case study of the Galapagos Islands due to: (1) the average temperatures of the Islands, which have no considerable variations. Therefore, tourists are present in the Islands throughout the entire year and there is no significant difference for holiday seasons (e.g., Christmas or summer) and hence an average value of water demand was used here. The daily variations and temperature influence on these variations was ignored in this step due to the lack of daily consumption registration. 
Table 2. Input information for the water supply component.

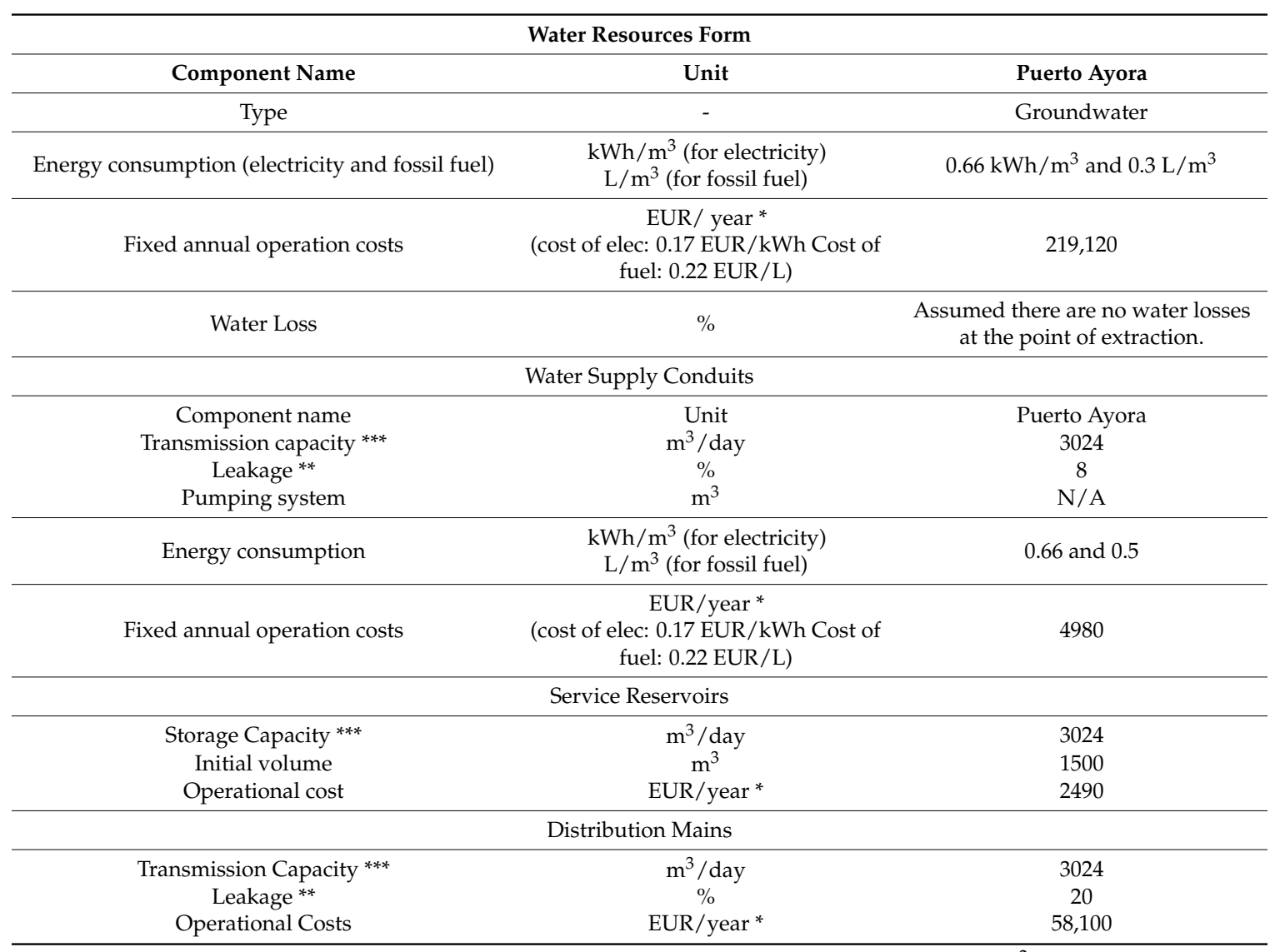

Note: There is no individual water treatment works with specifications defined in WaterMet ${ }^{2}$ for the case study.

* All the costs are based on information from the municipality ${ }^{* *}$ Leakage figure of $28 \%$ was used and not $35 \%$ as previously identified as Non-Revenue Water (NRW), due to calibration purposes. ${ }^{* * *}$ Transmission components in WaterMet ${ }^{2}$ (e.g., water supply conduits and distribution mains) are defined based on a daily transmission capacity expressed in $\mathrm{m}^{3}$ /day while storage components (e.g., service reservoirs) are defined based on storage capacity expressed in $\mathrm{m}^{3}$. The definition for transmission components is for a conceptual model used in WaterMet ${ }^{2}$ and is estimated based on the average hydraulic capacity of the components.

Table 3. Input information for the $\mathrm{WM}^{2}$ model sub-catchment component.

\begin{tabular}{ccc}
\hline Component Name & Unit & Puerto Ayora \\
\hline Topology & Defined as only one sub-catchment area and one local area \\
Number of properties & - & 1996 (domestic) \\
Total area & Ha & 163 \\
Current indoor water demand & $\mathrm{L} /$ cap/day & 160 \\
Current Industrial/Commercial water demand & $\mathrm{m}^{3} /$ day & 1200 \\
Average occupancy per property & Inhabitants/household & 4 \\
Roof area proportion & $(\%)$ & 40 \\
Pervious area proportion & $(\%)$ & 30 \\
Pavement \& road area proportion & $(\%)$ & 30 \\
Run-off coefficient & $(0-1)$ & 0.85 \\
Infiltration coefficient & $(0-1)$ & 0.9 \\
\hline
\end{tabular}

* Values calculated based on literature review [27].

"Water Resource Recovery" refers to RWH and GWR schemes. In this study, rainwater was assumed to be collected only from roof runoff and provide water for toilet flushing, showers, sinks, indoor irrigation and commercial uses. GWR collected from hand basins and showers was allocated only for toilet and indoor irrigation. The associated costs and energy was also considered for treatment and purification of RWH and GWR, since the existing supply system does not have any 
rainwater and/or greywater infrastructure; thus, these are considered as new alternatives. Other input information includes unit costs (of electricity and diesel fuel, water meter installation cost, and inflation rate), climate constants (elevation and geographical location to be used in rainfall-runoff modelling for calculation of evaporation), coefficients for all water demand categories, including percentage of conversion from water to wastewater (assumed here as 95\%), percentages of domestic water appliances and their possible energy consumptions, based on personal communications with personnel from the Municipality of Santa Cruz. The historic time series of weather data (e.g., precipitation, temperature and etc.) for the past 30 years were used here in the WaterMet ${ }^{2}$ model assuming that the same trend will take place in the future planning horizon. Time series data were obtained from the National Institute of Meteorology and Hydrology of Ecuador (INAMHI). It is relevant to mention that the annual average rainfall over the last years in Puerto Ayora is $380 \mathrm{~mm}$, but in other settlements located higher, such as in Bellavista the average is $1100 \mathrm{~mm}$ or even higher were the annual average can reach $2500 \mathrm{~mm}$ [28] having significant higher precipitation rates on the hot "invierno" season, than in the cold "garua" season, characterized by big and strong events of rain. On the other hand, the evapotranspiration average on both seasons is around $400 \mathrm{~mm}$.

The input data of 'Distribution Network Pipelines' about pipe materials, diameter and lengths were obtained from the municipality. These data were used for rehabilitation and leakage reduction in the water network.

\subsection{WaterMet ${ }^{2}$ Model Calibration}

The WaterMet ${ }^{2}$ model calibration in this study was done based on historical data of monthly water abstraction from the crevices serving as the water source of the UWS. The calibration parameters related to the capacity of the water resources in the WaterMet ${ }^{2}$ model were adjusted by using the monthly records on water abstraction available at the municipal water department. The calibration was performed with historical groundwater abstraction rates $\left(\mathrm{m}^{3} /\right.$ day), which were divided into two periods: year 2012 for calibration and year 2013 for validation. Figure 4a shows a graphical comparison of the performance of the model by plotting simulated versus observed figures. Later, they were likewise validated with the following period (year). The statistical correlation coefficient $\left(R^{2}\right)$ of 0.886 (Figure $4 \mathrm{~b}$ ) represents an acceptable value for this particular case study, regarding the lack of consistent data on the water pumping for supply, where daily records of water extractions for several days were missing. The value of the correlation obtained is significant based on the acceptable ranges suggested by other similar research works [22]. The model accuracy can be improved by increasing the amount of measured data used in calibration.

Based on the calibration and validation processes, the monthly coefficients of water demand profiles for Puerto Ayora applied in WaterMet ${ }^{2}$ were calculated (Table 4). These coefficients were calculated based on the supply average for that particular month and the total daily average supply average for the years chosen for validation and calibration (2012 and 2013). These were applied for the entire planning horizon and used for both domestic and industrial water demand. 


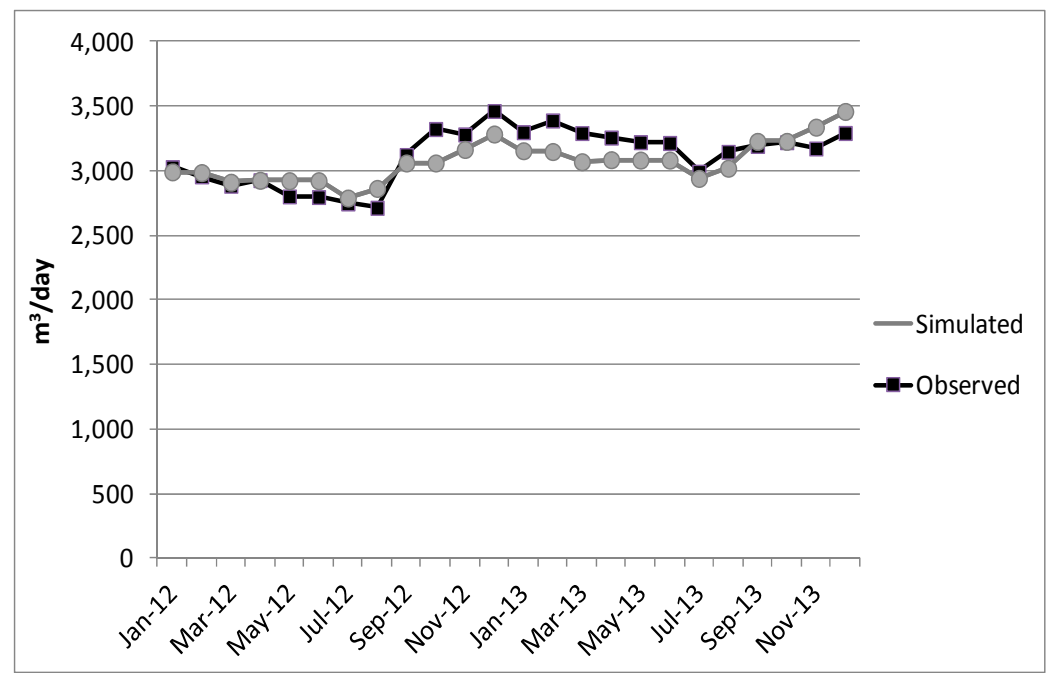

(a)

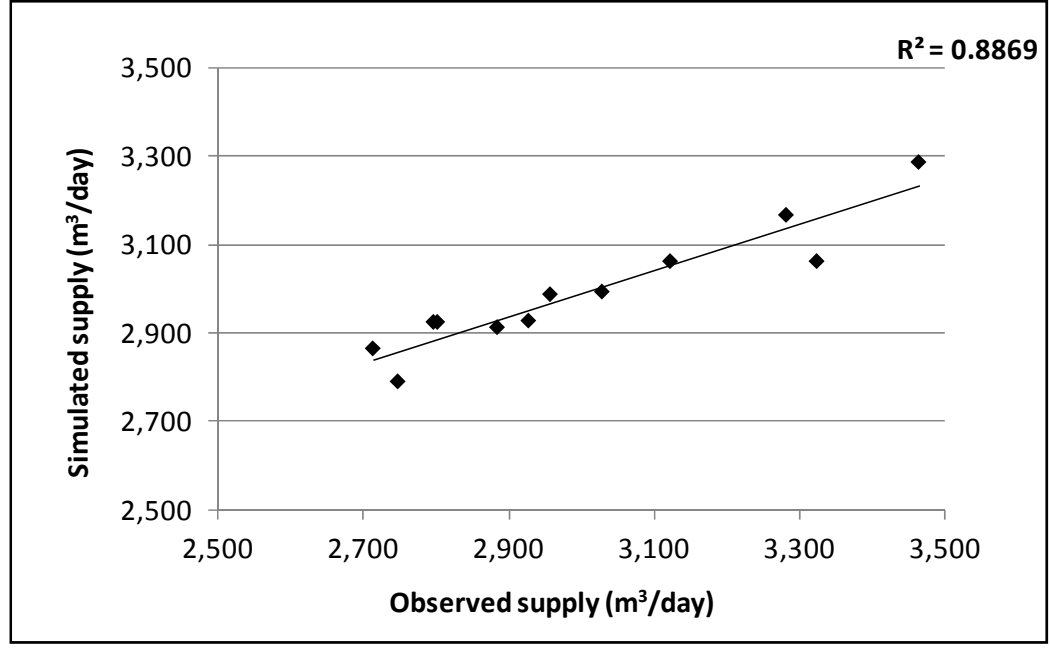

(b)

Figure 4. Comparison between simulated and recorded supply as (a) a time series of supply and (b) scatter plot.

Table 4. Selected monthly coefficients for Puerto Ayora.

\begin{tabular}{cc}
\hline Month & Puerto Ayora \\
\hline January & 1.027 \\
February & 1.019 \\
March & 0.991 \\
April & 0.993 \\
May & 0.967 \\
June & 0.965 \\
July & 0.922 \\
August & 0.941 \\
September & 1.014 \\
October & 1.050 \\
November & 1.036 \\
December & 1.080 \\
\hline
\end{tabular}




\subsection{Population and Tourist Growth Scenarios for Puerto Ayora}

The population growth scenarios were chosen based on the suggestions made by Mena et al., 2014 [6], according to historical growth and government planning. This was conducted by deriving relationship between the number of tourists and local residents in Galápagos, representing a demographic model with projections until 2033. Here, an ordinary least squares (OLS) linear regression was used to model the relationship based on population censuses in 1982, 1990, 2001 and 2010. This resulted in determining the number of residents in each year based on the corresponding number of tourist arrivals. Only land-based tourists were considered (excluding tourist cruise/ships). The growth scenarios were developed depending mainly on the migration rate since it is the primary demographic parameter due to the strong ties between the future growth of local residents and tourism growth. More specifically, the growth scenarios developed, based on Mena et al., 2014 [6] were defined as follows:

Slow growth: The tourist arrivals were 180,000 in 2012, therefore that number is considered to be the average per year. This scenario is suggested and preferred by environmentalists, NGOs and the Galápagos National Park.

Moderate growth: The tourist arrivals maintain an average annual increase of 7066 visitors (4\%). This figure was estimated from the recorded tourism growth in the last 20 years.

Fast growth: The tourist arrivals increase exponentially by an annual rate of $7 \%$. This scenario is preferred by the central government following their objective to increase tourism revenues in the whole country.

Very fast growth: The number of tourist arrivals would be eight times greater than the number of residents at the end of the planning horizon (i.e., in year 2044), suggesting a rate of annual growth of $9 \%$.

A summary of growth rates used in the four scenarios is shown in Table 5.

Table 5. Annual population and tourist growth scenarios used for water demand forecast.

\begin{tabular}{ccc}
\hline Growth Scenario & Local Population Increase & Tourist Visitors Increase * \\
\hline Very Fast & $7 \%$ & $9 \%$ \\
Fast & $5 \%$ & $7 \%$ \\
Moderate & $3 \%$ & $4 \%$ \\
Slow & $1 \%$ & $1 \%$ \\
\hline
\end{tabular}

* The historic average growth per year is $7 \%$.

\subsection{Alternatives and Intervention Strategies}

Six potential alternatives were developed in this study. These alternatives vary from those aiming to increase water supply (e.g., desalination plant construction or RWH and/or GWR) to those aiming to reduce demand (e.g., leakage reduction, water meter installation or any other form of general water demand management). All of these alternatives have been identified with the aim to balance the long-term water demand. The detailed description of all alternatives is shown in Table 6 . Leakage reduction and water meter installation are alternatives that have been proposed already over the last years; nevertheless, they have not yet been implemented [26]. With this study, we aim to quantify the impact of them in the short- and long-term. Furthermore, desalination with reverse osmosis has also been suggested due to popularity within authorities, since water quality issues (salinity) would also be improved. RWH has been proposed as a more sustainable option and due to the attractiveness in the smaller town of Bellavista. Moreover, GWR has also been proposed as a sustainable option as well and with the aim of reducing wastewater disposal, since the submerged membrane bioreactor (MBR) offers a low-footprint with a high quality effluent for recycling domestic water [29]. Finally, water demand management was also included, since the specific demand is currently considered high compared to other domestic demand in water scarce areas. Each alternative 
was analysed separately in order to assess the impact on the UWS. All of the previous proposed alternatives were discussed with the Department of Water and Sanitation of Santa Cruz. Some of them have already been proposed and some are new suggested alternatives.

The proposed alternatives were first simulated individually in the WaterMet ${ }^{2}$ model over the planning horizon (2014-2044) in order to analyze their impact to balance future water demand under different population/tourist growth scenarios. Table 7 shows the results of respective simulation model runs in terms of the fraction of the water demand delivered (i.e., covered) at the end of the planning horizon (year 2044), including the corresponding baseline at the start of the planning horizon (year 2014). This fraction is calculated as the ratio of the total water supplied to the total water demand over the long-term planning horizon. Due to unsatisfactory (i.e., low) fractions of water demand covered by supply for most of the individual alternatives (Table 7), these were combined to form five more complex intervention strategies (Figure 5).

Generally, the selected intervention strategies can start at any year during the planning horizon period. This study assumed that all the alternatives will be implemented starting at year 3 , in order to give time to the municipality to implement and construct the different infrastructure needed for each of the proposed alternatives. The combination of strategies aimed to complement each other, and to improve the fraction of water demand delivered at the end of the planning horizon. Intervention Strategy 5 is considered a combination of all sustainable alternatives, except the option with desalination.

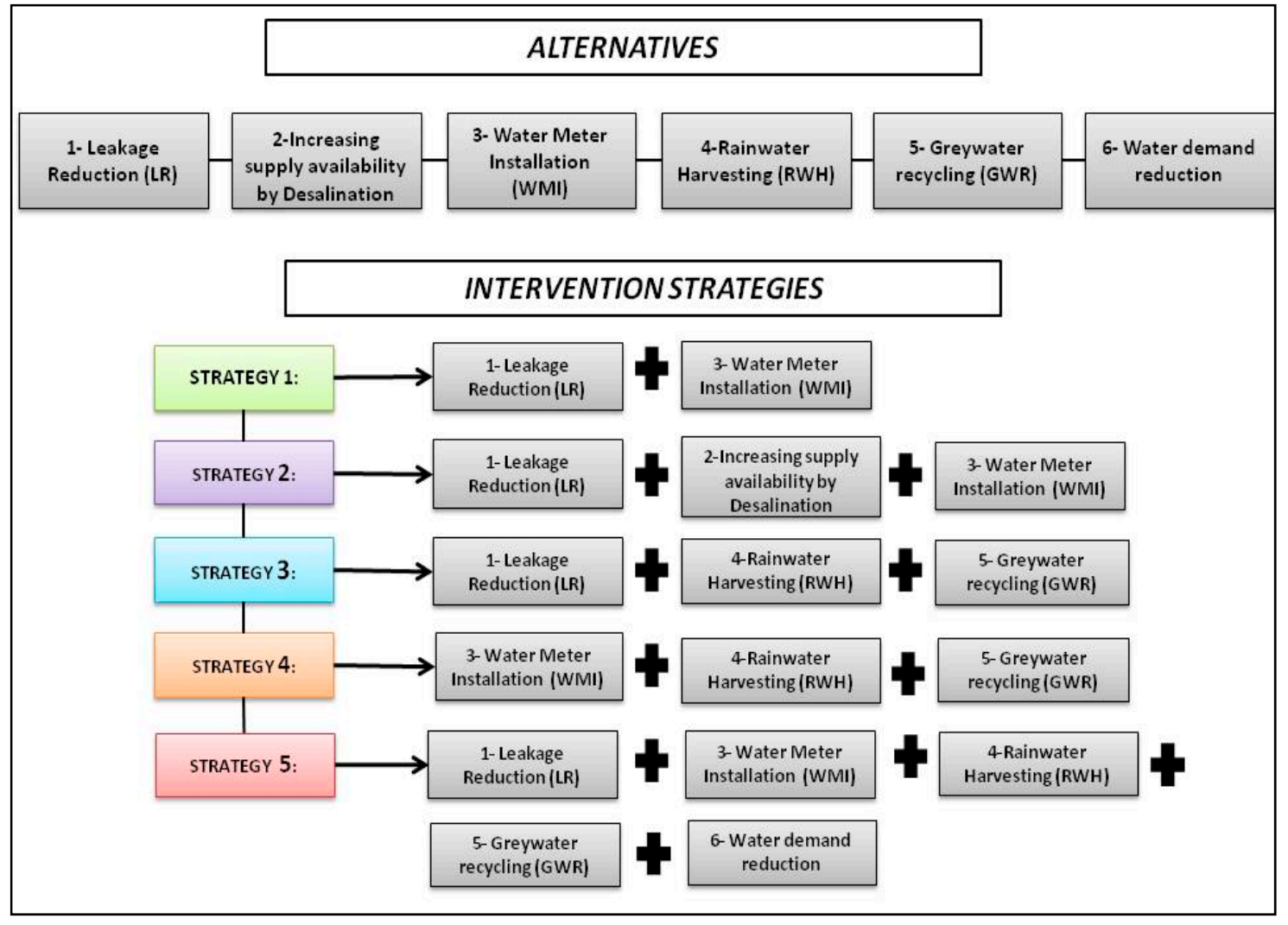

Figure 5. Intervention strategies applied to the UWS model. 
Table 6. Suggested alternatives for improvement of the UWS.

\begin{tabular}{|c|c|c|c|c|c|}
\hline Alternative & Description & Input Values & Assumptions & Total Costs $^{\mathrm{b}}\left(\mathrm{EUR} / \mathrm{m}^{3}\right)$ & Reference \\
\hline \multirow[t]{2}{*}{ (1) Leakage Reduction } & \multirow[t]{2}{*}{$\begin{array}{l}\text { Reduction from } 28 \%^{a} \text { to } 13 \% \\
\text { (1\% annually). }\end{array}$} & \multirow{2}{*}{$\begin{array}{l}\text { Energy consumption: } 0.66 \mathrm{KWh} / \mathrm{m}^{3} \\
\text { (current use of energy). The same values } \\
\text { for all four growth scenarios }\end{array}$} & $\begin{array}{l}\text { Installation of automatic and computerized leakage } \\
\text { and control system (e.g., pressure and flow } \\
\text { monitoring). }\end{array}$ & \multirow[t]{2}{*}{0.66} & \multirow{2}{*}{$\begin{array}{l}\text { Municipality of } \\
\text { Santa Cruz and } \\
\text { local providers }\end{array}$} \\
\hline & & & Replacement of old pipes (17,800 m of PVC pipes). & & \\
\hline (2) Desalination Plant & $\begin{array}{l}\text { Installation of a new SWRO } \\
\text { desalination plant (BWRO was not } \\
\text { considered to avoid extra pressure on } \\
\text { the basal aquifer and increase of } \\
\text { salinity) with energy recovery system. } \\
\text { Open seawater intake }(35,000 \mathrm{ppm}) \text {, } \\
55 \% \text { recovery rate, } 99 \% \text { salt rejection. }\end{array}$ & $\begin{array}{l}\text { (1) small growth }\left(9000 \mathrm{~m}^{3} / \text { day) }\right. \\
\text { (2) moderate growth }\left(16,000 \mathrm{~m}^{3} / \text { day }\right) \\
\text { (3) fast growth }\left(28,000 \mathrm{~m}^{3} \text { day }\right) \\
\text { (4) very fast growth }\left(50,000 \mathrm{~m}^{3} / \text { day) }\right. \\
\text { Energy consumption } \mathrm{c}: 3 \mathrm{KWh} / \mathrm{m}^{3}\end{array}$ & $\begin{array}{l}\text { Cost includes plant, land, civil works and } \\
\text { amortization costs, chemicals for pre and post water } \\
\text { treatment, energy requirement, brine dissolution } \\
\text { and discharge, cooling towers(including electricity } \\
\text { and steam), spares and maintenance (including } \\
\text { membrane replacement every } 5 \text { years), and labour. }\end{array}$ & $\begin{array}{l}\text { (1) } 1.27, \\
\text { (2) } 1.25, \\
\text { (3) } 1.23 \\
\text { (4) } 1.22\end{array}$ & [30-33] \\
\hline $\begin{array}{l}\text { (3) Water Meter } \\
\text { Installation }\end{array}$ & $\begin{array}{l}\text { Installation of water meters per } \\
\text { premise with a rate of } 10 \% \text { annually. }\end{array}$ & $\begin{array}{l}140 \text { EUR/unit (including installation and } \\
\text { maintenance) The same unit cost for all } \\
\text { growth scenarios }\end{array}$ & Installation of Flodis-single jet turbine device) & 0.04 & $\begin{array}{l}\text { Municipality of } \\
\text { Santa Cruz }\end{array}$ \\
\hline $\begin{array}{l}\text { (4) Rainwater } \\
\text { Harvesting }\end{array}$ & $\begin{array}{l}\text { Installation of a household rainwater } \\
\text { harvesting tank for indoor and/or } \\
\text { outdoor use }\left(2 \mathrm{~m}^{3}\right)\end{array}$ & $\begin{array}{l}\text { Capacity calculated as } 4000 \mathrm{~m}^{3} \text { (approx. } \\
2000 \text { households) Energy consumption: } 2 \\
\mathrm{Kwh} / \mathrm{m}^{3}\end{array}$ & $\begin{array}{l}\text { Water collected from roofs only }{ }^{\mathrm{e}} \text {. The collected } \\
\text { rainwater used for toilet flushing, hand and kitchen } \\
\text { basin, showers and outdoor use. The cost includes } \\
\text { purchase cost of tank, pumping, delivery and } \\
\text { installation, household plumbing, and mains water } \\
\text { switching devices, energy consumption, } \\
\text { maintenance and pump replacement (every ten } \\
\text { years). }\end{array}$ & 0.21 & [34-36] \\
\hline $\begin{array}{l}\text { (5) Greywater } \\
\text { Recycling }\end{array}$ & $\begin{array}{l}\text { Installation of single house on-site } \\
\text { and decentralized greywater } \\
\text { treatment using a submerged } \\
\text { membrane (MBR), including } \\
\text { disinfection unit }\end{array}$ & $\begin{array}{l}\text { Based on household greywater treatment } \\
\text { capacity of } 350 \mathrm{~L} \text { capacity and } 2000 \\
\text { households; } 5 \text { inhabitants per household } \\
\text { and } 163 \text { Lpcpd }{ }^{\mathrm{d}} \text {. Flow capacity of } 200 \\
\text { L/population equivalent }\end{array}$ & $\begin{array}{l}\text { Greywater collected from kitchen, hand basins and } \\
\text { showers, which account to approximately } 48 \% \text { of } \\
\text { total water demand). Household treatment } \\
\text { assumed with membrane bioreactor plant } \\
\text { (biological treatment, aeration, and membrane } \\
\text { filtration. Treated greywater used on-site for toilet } \\
\text { flushing and outdoor use. }\end{array}$ & 1.08 & [37-41] \\
\hline $\begin{array}{l}\text { (6) Water Demand } \\
\text { Reduction }{ }^{\mathrm{f}}\end{array}$ & $\begin{array}{l}\text { Reduction of specific demand of } \\
\text { municipal water }\end{array}$ & $\begin{array}{l}\text { Reduction from } 163 \text { lpcpd }{ }^{d} \text { to } 120 \text { lpcpd } \\
d \text { (assuming } 1 \% \text { annual reduction on } \\
\text { water demand starting in year } 3 \text {, in order } \\
\text { to complete the reduction at the end of } \\
\text { the planning horizon }\end{array}$ & $\begin{array}{l}\text { Assumed the change of "water tariff" structure to } \\
\text { reduce the average specific demand }\end{array}$ & - & - \\
\hline
\end{tabular}

${ }^{\mathrm{a}}$ This value was considered for calibration purposes ${ }^{\mathrm{b}}$ Total costs include investment costs, operations and managements costs, interest rate and extra costs and the municipality will towards the lower side; ${ }^{\mathrm{d}}$ lpcpd corresponds to litres per capita per day; e Only runoff from roof was considered since, pavement/road run-off will incur in a significant extra cost for water treatment; ${ }^{\mathrm{f}}$ It is assumed that adjustment for water tariff as an intervention by the water utility can lead to water demand reduction, based on previous studies and policy from the municipality. Only capital investment and Operations \& Management costs are analysed. 
Table 7. Fraction of the water demand delivered.

\begin{tabular}{cccccccc}
\hline $\begin{array}{c}\text { Population } \\
\text { Growth }\end{array}$ & Baseline & Alternative 1 & Alternative 2 & Alternative 3 & Alternative 4 & Alternative 5 & Alternative 6 \\
\hline Slow & 0.52 & 0.64 & 1.00 & 0.68 & 0.72 & 0.79 & 0.73 \\
Moderate & 0.35 & 0.36 & 1.00 & 0.37 & 0.40 & 0.43 & 0.41 \\
Fast & 0.17 & 0.17 & 0.99 & 0.18 & 0.21 & 0.22 & 0.20 \\
Very Fast & 0.10 & 0.11 & 1.00 & 0.11 & 0.16 & 0.13 & 0.12 \\
\hline
\end{tabular}

\section{Results and Discussion}

The current situation (baseline) and the selected intervention strategies were analysed and evaluated with respect to a number of key performance indicators (KPI) for a 30-year planning horizon. The KPIs used here for comparison of the different selected strategies are total water demand, percentage of water demand coverage (i.e., fraction of water demand delivered), consumption per capita, energy consumption, and costs (capital and O\&M), for each growth scenario.

Figure 6 shows the results of the Puerto Ayora case study. These figures portray results of year 30, since based on the population and tourism growth scenarios, it has been considered as the most critical year. Obviously, the most severe growth scenario is the very fast growth scenario, which is driven by the governmental objective to optimise tourist revenues for the country.

Based on Figure $6 a$, it can be inferred that the current infrastructure would not suffice for any of the population growth scenarios, since a $70 \%$ coverage of demand with supply could hardly be reached even with the slow growth scenario, and in the very fast scenario hardly $20 \%$ coverage could be achieved. This also shows that the current situation is not as perceived, since based on the volume of water supplied, the current coverage is calculated as $91 \%$. However, the local community considers the coverage to be less [42]. Figure $6 \mathrm{~b}$ shows that only Strategy 2, which includes desalination, will fully cover the water demand by the end of the planning horizon, for all growth scenarios. This suggests that current growth trends are exorbitant and will generate a significant local population and tourism demand of water. Nevertheless, Strategy 5 (a combination of all alternatives, except desalination) will be sufficient, but only in the slow growth case scenario, which has been the one preferred by all NGOs and conservation authorities, but highly unlikely [6].

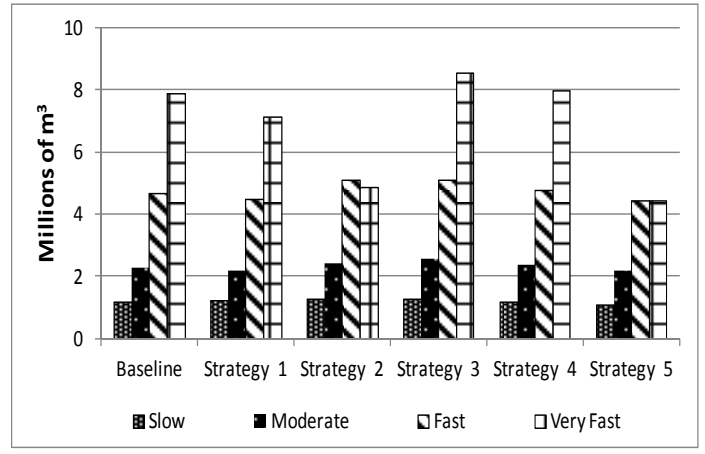

(a)

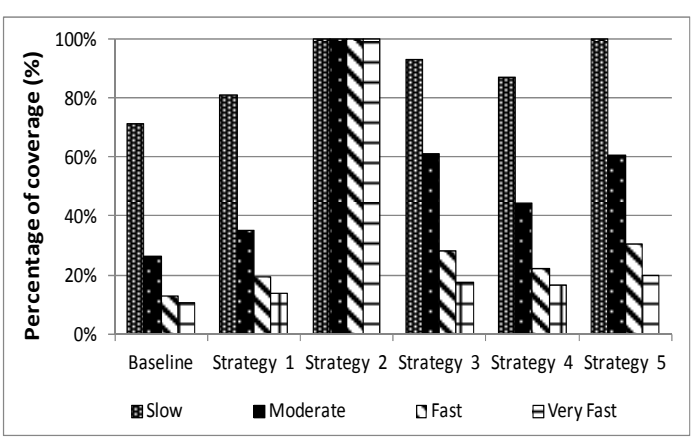

(b)

Figure 6. (a) Total water demand by 2030 for various growth scenarios and (b) Percentage of demand coverage by supply in 2030 for various intervention strategies in Puerto Ayora.

Strategy 2 increases water availability by installation of a new desalination plant, complying with water demand over the planning horizon. Therefore, even though the other strategies have been suggested to avoid such an investment and greater potential environmental impacts on the island, they cannot meet the demand in 30 years. The best strategy to save on total water demand, reducing pressure on the supply system and infrastructure, is Strategy 5, for all growth scenarios. This is because Strategy 5 is the only one that considers and contributes to proper demand management, 
reducing current specific demand by $40 \mathrm{~L} / \mathrm{cap} /$ day at the end of the planning horizon. However, is still insufficient for 100\% coverage of demand in year 2044 and therefore cannot cope with the future proposed growths; except in the slow growth scenario.

Regarding costs and energy use shown in Figure 7 as expected, Strategy 2 seems best, being significantly higher than the other intervention strategies. These costs refer to the total unit cost and the total water demand for the year 2044. The costs vary for each growth scenario, making the fast and very fast more unsuitable due to the enormous financial burden. This makes reference also to a higher investment (depending on the plant size calculated per growth scenario), as well as operation and management costs, implicated with a desalination plant and a much higher energy use for desalination treatment and process, compared to the other strategies, regarding this particular case study. Since this archipelago is located approximately $1000 \mathrm{~km}$ from the mainland, fuel for producing electricity needs to be imported from the mainland, adding extra costs to this option. Furthermore, GWR also has high costs due to pumping costs and investment per installed unit.It is assumed that all the pumps modelled here are operated and maintained by the municipality only; nevertheless, it is more environmentally friendly since it reduces wastewater and water demand. The most economical strategies are 1 and 4, which include leakage reductions, water meter installation, as well as rainwater and GWR. Even though Strategies 3 and 4 are pretty similar because they both have RWH and GWR, the influence of water meter installation is more positive and therefore the costs reduce. On the other hand, Strategy 5 has the highest costs after Strategy 3, because it includes all of the alternatives,; therefore, the costs for leakage reduction alternative (replacement of pipes and an automated leakage control system) as well as GWR are pretty significant. Regarding the energy consumption in year 30, Strategy 2 is three to four times higher than the other strategies $\left(4 \mathrm{KwH} / \mathrm{m}^{3}\right)$. Regarding energy use, the best option is Strategy 5, because it decreases water demand. The other strategies do not seem to vary much in the energetic consumption compared to the current situation. The aggregated annual energy consumption for other strategies has minor change compared to the baseline due to low volume of water supplied by RWH or GWR compared to the total water supplied by the mains.

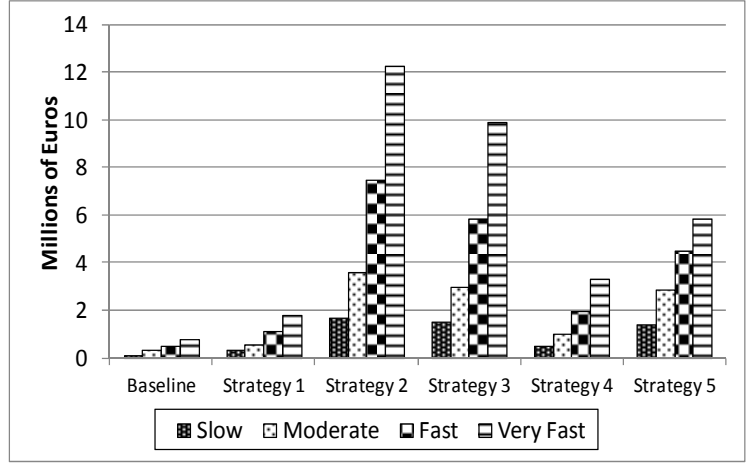

(a)

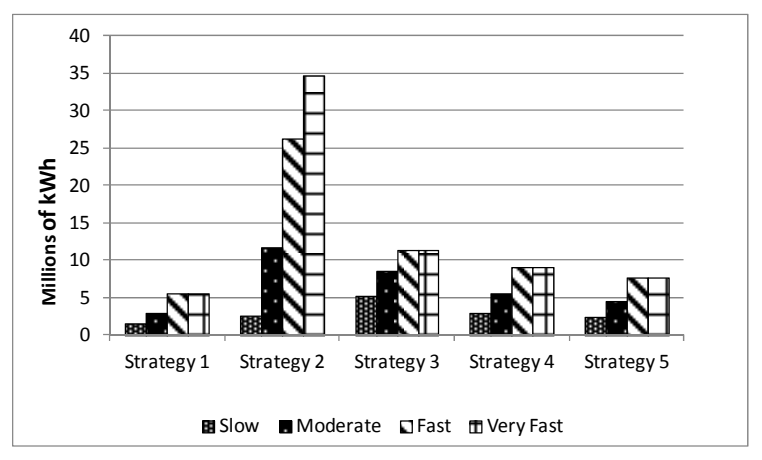

(b)

Figure 7. (a) Total costs for year 30 and (b) Total energy use for year 30 for various intervention strategies and growth scenarios in Puerto Ayora.

Furthermore, Figure 8 shows the variations of water demand delivered to consumers over the planning horizon for different strategies and for the scenarios of slow and very fast growth only. As can be observed from this figure, the first peaks on both diagrams occur in year 3, when the alternatives are implemented. The rest of the peaks can be explained by the influence of meteorological data, making some years better for rainwater harvesting (and GWR) than the others. Therefore, based on historical precipitation rates, the methodology adopted predicts similar variation for the future, directly affecting rainwater collected by every individual household, making some years better than the others. Also, greywater is influenced, since in peak years, the amount of rainwater contributing to the water demand delivered is higher. Strategy 1's percentages of coverage have a decreasing 
tendency over the years, which is more abrupt in the very fast scenario. On the other hand, Strategy 2 's percentages of coverage remain constant due to the increase in the transmission capacity and availability of water. In addition, Strategies $3-5$ are influenced by rainfall levels, since rainwater is considered as an alternative in these three. The variations between these last three strategies are due to the combination of different alternatives, regarding water meter installation, leakage reduction and water demand reduction.

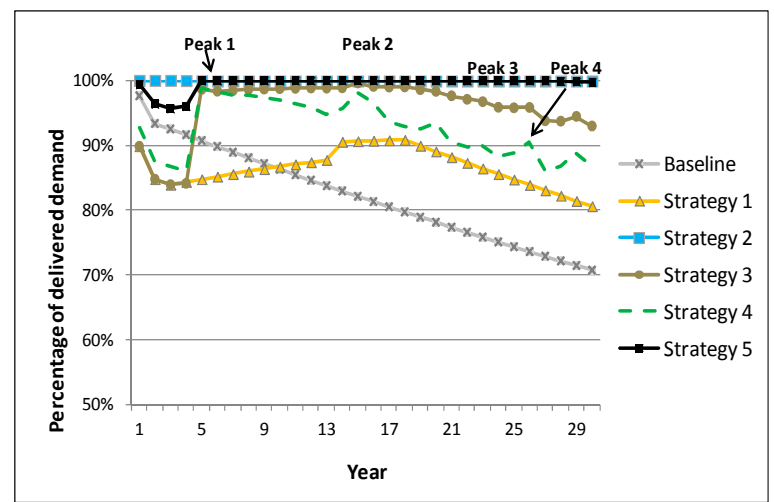

(a)

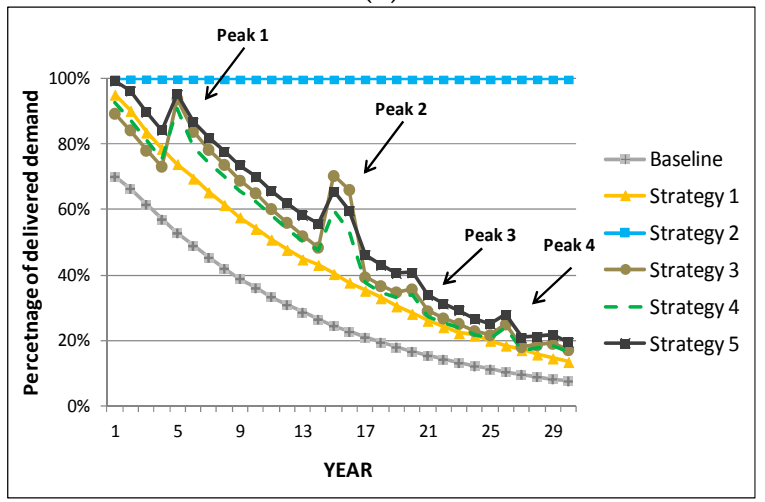

(b)

Figure 8. Coverage of demand with supply over the planning horizon for the (a) slow growth and (b) very fast growth scenarios in Puerto Ayora.

Figure 9 shows the impact and evolution of different intervention strategies regarding the calculated per capita demand. This was calculated based on the prognoses of population growth for every year and for each scenario. In the slow growth scenario, the specific demands for all strategies have more or less the same tendency to decrease at the end of the planning horizon, but not necessarily because of the reduction of consumption per capita, but due to the amount of total water divided by more people every year. The highest per capita consumption is observed for Strategies 2 and 3, which, as stated before, are the strategies that involve the increase of water availability. Moreover, Strategy 5 has a significant impact regarding the reduction of households' consumption and use, especially toward the end of planning horizon, where the per capita figure tends to decrease. In the case of very fast growth, the per capita consumption trends vary between strategies, reflecting each alternative selected and the type of population growth scenario. Unexpectedly, none of the strategies reduce per capita water consumption from the baseline scenario, but all of them will increase these figures over the years. Strategy 2 seems to increase per capita consumption 2-3 times more when compared to other strategies, but this means that this strategy allows the customers to be completely satisfied without the need to reduce it. Nevertheless, these values reduce at the end of the planning horizon and stay within reasonable margins because of the large projected population for the latest years. 


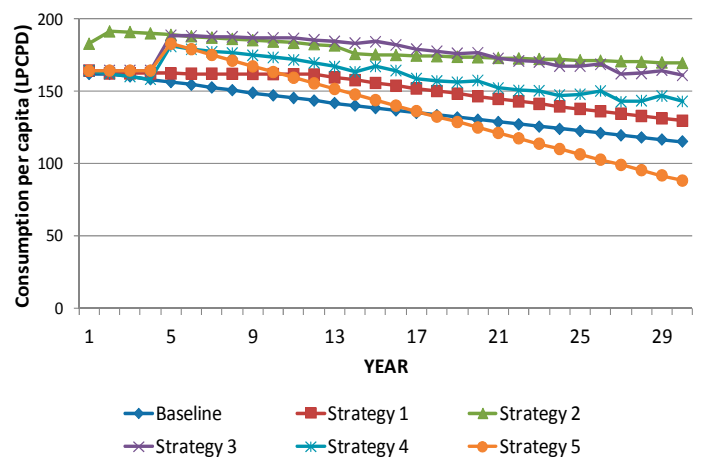

(a)

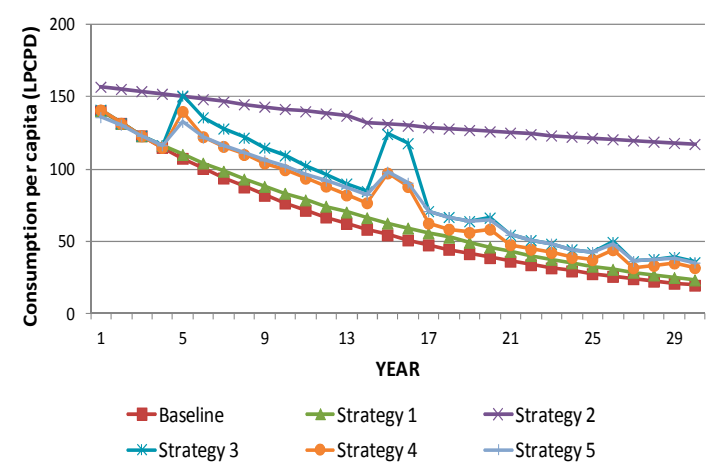

(b)

Figure 9. Consumption per capita over the planning horizon for the (a) slow growth and (b) very fast growth scenarios.

Also, current climate change impacts should be taken into account. This means that more extreme events of less or more precipitation may affect several strategies, such as the rainwater harvesting. Also, these possible events may affect even more the unbalance of the basal aquifer for the strategies that consider brackish water (strategies with leakage reduction, grey water recycling, water meter installation and per capita demand reduction). This may suggest that the quality of the water could reduce significantly, limiting its uses even more than in the current situation. Therefore, these strategies could be complemented by other individual alternatives, making them more complex. Furthermore, this suggests once again that the desalination option needs to be further considered due to the many factors already presented.

\section{Conclusions}

This paper addresses the issue of long-term water supply/demand balance for the main town in the Galápagos Island of Santa Cruz. To address this, a WaterMet ${ }^{2}$ model capable of simulating the water balance over a 30-year period was built and calibrated. Five possible intervention strategies were defined by first considering six individual alternatives, aiming at either increasing supply by using alternative water sources (e.g., desalination water plant construction, rainwater harvesting and GWR) or reducing future water demand (leakage reduction, water meter installation and water demand management). The impact of these strategies on the water system performance was evaluated by using the aforementioned WaterMet ${ }^{2}$ model with suitable KPIs and under four scenarios of population growth. The KPIs appear to be very sensitive to the population growth, actual water demand (domestic and tourist) and leakage levels, which have been estimated, based on other studies, but would need to be verified by further research.

Clearly, the current infrastructure would not be sufficient for any growth scenario, suggesting that fast and very fast scenarios are unsustainable and unaffordable. The results obtained show that the most viable strategy with respect to water demand coverage (i.e., fraction of future water demand cover by supply) in all population growth scenarios is to install a desalination plant. However, this would increase the energy consumption drastically; exerting extra pressure on the current thermal plant and implying additional fuel importation from the mainland, increasing costs and negative environmental impacts. Moreover, the disposal of brine is likely to be a potential problem and the costs of this option implicate a high investment that most likely cannot be afforded by the local municipality. As stated by the study by Dhakal et al. [43], desalination options are still the most energy intensive technology to produce drinking water and, being implemented most of the time as a last resort where conventional freshwater resources have been stretched to the limit. Furthermore, it produces considerable amounts of Green House Gas emissions if fossil energy sources are used. 
None of the suggested strategies would suffice for the moderate, fast and the very fast scenarios, expect for Strategy 2 (a combination of desalination, water meter installation and leakage reduction). Because of high potential environmental impacts associated with this strategy, a more sustainable option is to apply Strategy 5 (a combination of all alternatives, except desalination. However, if the annual population and tourist growth continue as the governmental objectives suggest, this strategy would not meet the expected future water demand. Furthermore, the uncontrolled water abstraction from crevices resulting from Strategy 5 may lead to infiltration of seawater, compromising the water quality in the aquifer and making it unusable. As already identified by Pryet et al. [44], the current aquifer where La Camiseta crevice is located, has high infiltration potential, weak rainfall and probably negligible recharge. Finally, the water demand management program suggested in Strategy 5 would impact positively on the specific water consumption and hence would alleviate the need for additional supply.

A number of other analyses could and must be done in the future, which are out of the scope of this paper. A combination of other alternatives could be further investigated, such as desalination for potable water (drinking and cooking) and the use of brackish water for all other requirements, in combination with rainwater harvesting and GWR. Nevertheless, climate change could be a reason to reconsider rainwater harvesting; if the supply system becomes highly dependent on this source, it would consequently be dependent on the weather. This also implies a further calibration of the meteorological data before a decision involving rainwater can be taken with confidence. Finally, as observed in Strategy 5, the reduction of per capita water demand would have a considerable influence on the future supply/demand balance. Therefore, other water demand management strategies (e.g., using water-efficient appliances and fitting, especially inefficient toilets which account for $49 \%$ of total household demands) should be further investigated in the future researches.

The WaterMet ${ }^{2}$ methodology has been shown to be a useful and practical software for data limited and small case studies. The current study also demonstrated that WaterMet ${ }^{2}$ can provide a holistic approach in modelling urban water systems under current and various future scenarios.

Acknowledgments: We would like to thank Secretaría Nacional de Educación Superior, Ciencia y Tecnología (SENESCYT) for the fellowship granted. Also, we would like to thank the Department of Potable Water in Puerto Ayora-Galápagos, and special thanks to Delio Sarango for his input, time and availability for all data of the case study.

Author Contributions: Maria Fernanda Reyes collected the data, modelled it and wrote the paper. Kourosh Bezhadian contributed with the modelling, fixing of the model and writing of the paper. Nemanja Trifunovic, Saroj Sharma, Maria D Kennedy and Zoran Kapelan contributed to the writing of the paper, analysis and interpretation of results.

Conflicts of Interest: The authors declare no conflict of interest. The founding sponsors had no role in the design of the study; in the collection, analyses, or interpretation of data; in the writing of the manuscript, and in the decision to publish the results.

\section{References}

1. Epler, B. Tourism, the Economy, Population Growth, and Conservation in Galapagos; Report for Charles Darwin Foundation; Charles Darwin Foundation: Puerto Ayora, Ecuador, 2007.

2. Independent National Electoral (INEC). Censo de población y vivienda del Ecuador 2010. Ecuador, Instituto Nacional de Estadísticas y Censos, 2010. Available online: http:/ / www.ecuadorencifras.gob.ec (accessed on 1 September 2015).

3. DPNG Dirección del Parque Nacional Galápagos. 2016. Available online: http://www.galapagospark.org/ (accessed on 5 February 2016).

4. González, J.A.; Montes, C.; Rodríguez, J.; Tapia, W. Rethinking the Galapagos Islands as a complex social-ecological system: Implications for conservation and management. Ecol. Environ. 2008, 13, 13. [CrossRef]

5. Pizzitutti, F.; Mena, C.F.; Walsh, S.J. Modelling tourism in the Galapagos Islands: An agent-based model approach. J. Artif. Soc. Soc. Simul. 2014, 17, 14. [CrossRef] 
6. Mena, C. Determination of Social, Environmental and Economic Relations which Allow the Development Based on Different Processes of Modelling, Potential Scenarios of Sustainability of the Socio-Ecological System of the Galapagos Islands with Emphasis on the Dynamic of the Flux of Tourist Visitors; Report for the Ministry of Environment; the Ministry of Environment: Puerto Ayora, Ecuador, 2014; unpublished.

7. Reyes, M.; Trifunovic, N.; Sharma, S.; Kennedy, M. Data Assessment for Water Demand and Supply Balance in the Island of Santa Cruz (Galápagos Island). Desalin. Water Treat J. 2015. [CrossRef]

8. Watkins, G.; Cruz, F. Galapagos at Risk: A Socioeconomic Analysis; Report for Charles Darwin Foundation; Charles Darwin Foundation: Puerto Ayora, Ecuador, 2007.

9. Proctor and Redfern CA. Estudio De Provisión De Agua y Tratamiento De Aguas Residuales De Santa Cruz; Proctor and Redfern International Limited: Santa Cruz-Galápagos, Ecuador, 2003.

10. Reyes, M.; Trifunovic, N.; Sharma, S.; Kennedy, M. Implications of Water Tariff Structure on Water Demand in Santa Cruz Island (Galapagos Archipelago). In Proceedings of the XVth World Water Congress, Edinburgh, Scotland, UK, 25-29 May 2015.

11. D'Ozouville, N.; Deffontaines, B.; Benveniste, J.; Wegmüller, U.; Violette, S.; De Marsily, G. DEM generation using ASAR (ENVISAT) for addressing the lack of freshwater ecosystems management, Santa Cruz Island, Galápagos. Remote Sens. Environ. 2008, 112, 4131-4147. [CrossRef]

12. Reyes, M.; Trifunovic, N.; d'Ozouville, N.; Sharma, S.; Kennedy, M. Quantification of urban water demand in the Island of Santa Cruz (Galápagos Archipelago). Desalin. Water Treat. 2017, 64, 1-11.

13. Behzadian, K.; Kapelan, Z.; Venkatesh, G.; Brattebø, H.; Sægrov, S.; Rozos, E.; Makropoulos, C. Quantitative UWS Performance Model: WaterMet ${ }^{2}, 2014$, TRUST Report. Available online: https://ore.exeter.ac. uk/repository / bitstream/handle/10871/17062/d332-Final.pdf?sequence=1\&isAllowed=y (accessed on 25 May 2016).

14. Mitchell, V.G.; Diaper, C. UVQ User Manual urban water balance and contaminant balance analysis tool. CSIRO Version1 2010, 2, 2005-2282.

15. Dos Santos, C.C.; Pereira Filho, A.J. Water Demand Forecasting Model for the Metropolitan Area of São Paulo, Brazil. Water Resour. Manag. 2014, 28, 4401-4414. [CrossRef]

16. Billings, R.B.; Jones, C.V. Forecasting Urban Water Demand; American Water Works Association: Denver, CO, USA, 2008.

17. Ajbar, A.; Ali, E. Prediction of municipal water production in touristic Mecca City in Saudi Arabia using neural networks. J. King Saud Univ. Eng. Sci. 2015, 27, 83-91. [CrossRef]

18. Soyer, R.; Roberson, J.A. Urban Water Demand Forecasting: A Review of Methods and Models; American Society of Civil Engineers: Reston, VA, USA, 2010.

19. Mitchell, V.; Duncan, H.; Inma, R.M.; Stewart, J.; Vieritz, A.; Holt, P.; Grant, A.; Fletcher, T.; Coleman, J.; Maheepala, S. State of the art review of integrated urban water models. Novatech Lyon France 2007, 1, 507-5014.

20. Makropoulos, C.K.; Natsis, K.; Liu, S.; Mittas, K.; Butler, D. Decision support for sustainable option selection in integrated urban water management. Environ. Model. Softw. 2008, 23, 1448-1460. [CrossRef]

21. Last, E. City Water Balance: A New Scoping Tool for Integrated Water Management Options. Ph.D. Thesis, Univeristy of Birmingham, Birmingham, UK, 2010.

22. Behzadian, K.; Kapelan, Z. Modelling metabolism based performance of an urban water system using WaterMet ${ }^{2}$. Resour. Conserv. Recycl. 2015, 99, 84-99. [CrossRef]

23. Behzadian, K.; Kapelan, Z. Advantages of integrated and sustainability based assessment for metabolism based strategic planning of urban water systems. Sci. Total Environ. 2015, 527, 220-231. [CrossRef] [PubMed]

24. Sharma, S. Urban Water Supply and Demand Management; Lecture Notes; UNESCO-IHE (Institute for Water Education): Delft, The Netherlands, 2014.

25. Trifunovic, N. Introduction to Urban Water Distribution: Unesco-IHE Lecture Note Series; CRC Press: Boca Raton, FL, USA, 2006.

26. Reyes, M.; Trifunovic, N.; Sharma, S.; Kennedy, M. Assessment of Domestic Consumption in Puerto Ayora Intermittent Supply System (Santa Cruz Island-Galápagos). Manuscr. Rev. J. Water Supply Res. Technol. 2017, under review.

27. D'Ozouville, N. Water Resource Management: The Pelican Bay Watershed; Galápagos Report 2007-2008, 2009. Available online: https://www.galapagos.org/wp-content/uploads/2012/04/biodiv11-waterresource-mgmt.pdf (accessed on 12 August 2017). 
28. Domínguez, C.; Pryet, A.; Vera, G.M.; Gonzalez, A.; Chaumont, C.; Tournebize, J.; Villacis, M.; d'Ozouville, N.; Violette, S. Comparison of deep percolation rates below contrasting land covers with a joint canopy and soil model. J. Hydrol. 2016, 532, 65-79. [CrossRef]

29. Gobierno Autonomo Descentralizado Municipio de Santa Cruz. Atlás Geográfico del Cantón Santa Cruz; Secretaria Técnica de Planificación y Desarrollo Sustentable del Gobierno Autonomo Municipal Descentralizado de Santa Cruz: Santa Cruz- Galápagos, Ecuador, 2012; p. 50. (In Spanish)

30. Verrecht, B.; Maere, T.; Benedetti, L.; Nopens, I.; Judd, S. Model-based energy optimisation of a small-scale decentralised membrane bioreactor for urban reuse. Water Res 2010, 44, 4047-4056. [CrossRef] [PubMed]

31. Ghaffour, N.; Missimer, T.; Amy, G. Technical review and evaluation of the economics of water desalination: Current and future challenges for better water supply sustainability. Desalination 2013, 309, 197-207. [CrossRef]

32. Al-Karaghouli, A.; Kazmerski, L. Energy consumption and water production cost of conventional and renewable-energy-powered desalination processes. Renew. Sustain. Energy Rev. 2013, 24, 343-356. [CrossRef]

33. Watereuse Association Desalination Committee. Seawater Desalination Costs: White Paper, 2011. Available online: https://watereuse.org/wp-content/uploads/2015/10/WateReuse_Desal_Cost_White_ Paper.pdf (accessed on 12 August 2017).

34. Lattemann, S.; Kennedy, M.D.; Schippers, J.C.; Amy, G. Global desalination situation. Sustain. Sci. Eng. 2010, 2, 7-39.

35. Tam, V.W.Y.; Tam, L.; Zeng, S.X. Cost effectiveness and tradeoff on the use of rainwater tank: An empirical study in Australian residential decision-making. Resour. Conserv. Recycl. 2010, 54, 178-186. [CrossRef]

36. Retamal, M.; Turner, A.; White, S. Energy implications of household rainwater systems. Aust. Water Assoc. 2009, 38, 70-75.

37. Hauber-Davidson, G.; Shortt, J. Energy Consumption of Domestic Rainwater Tanks. Water J. 2011, 3, 1-5.

38. Fletcher, H.; Mackley, T.; Judd, S. The cost of a package plant membrane bioreactor. Water Res. 2007, 41, 2627-2635. [CrossRef] [PubMed]

39. Boehler, M.; Joss, A.; Buetzer, S.; Holzapfel, M.; Mooser, H.; Siegrist, H. Treatment of toilet wastewater for reuse in a membrane bioreactor. Water Sci. Technol. 2007, 56, 63-70.

40. Gnirss, R.; Luedicke, C.; Vocks, M.; Lesjean, B. Design criteria for semi-central sanitation with low pressure network and membrane bioreactor-The ENREM project. Water Sci. Technol. 2008, 57, 403-410. [CrossRef] [PubMed]

41. Fountoulakis, M.; Markakis, N.; Petousi, I.; Manios, T. Single house on-site grey water treatment using a submerged membrane bioreactor for toilet flushing. Sci. Total Environ. 2016, 551, 706-711. [CrossRef] [PubMed]

42. Guyot-Tephany, J.; Grenier, C.; Orellana, D. Uses, Perceptions and Management of Water in Galápagos; Galapagos Report 2011-2012; GNPS, GCRG, CDF and GC: Puerto Ayora, Galápagos, Ecuador, 2013.

43. Dhakal, N.; Salinas Rodriguez, J.C.; Schippers, J.C.; Kennedy, M.D. Perspectives and challenges for desalination in developing countries. IDA J. Desalin. Water Reuse 2014, 6, 10-14. [CrossRef]

44. Pryet, A.; Dominguez, C.; Tomai, P.F.; Chaumont, C.; d'Ozouville, N.; Villacís, M.; Violette, S. Quantification of cloud water interception along the windward slope of Santa Cruz Island, Galapagos (Ecuador). Agric. For. Meteorol. 2012, 161, 94-106. [CrossRef]

(C) 2017 by the authors. Licensee MDPI, Basel, Switzerland. This article is an open access article distributed under the terms and conditions of the Creative Commons Attribution (CC BY) license (http://creativecommons.org/licenses/by/4.0/). 